\title{
O Direito humano ao sorriso: uma análise do arcabouço legislativo sobre a saúde bucal
}

The human right to smile: an analyses of the legislative outline about oral health

El derecho humano a sonreír: un análisis del contorno legislativo sobre la salud oral

Yêda Maria Parro ${ }^{1}$

André Vinicius Pires Guerrero²

RESUMO: A saúde bucal da população tem reflexo na saúde integral e na qualidade de vida de toda a sociedade. As mudanças nos padrões das doenças guardam estreita relação com as alterações nos estilos de vida, que incluem dietas ricas em açúcares, uso de tabaco e álcool, sedentarismo e estresse crônico. Assim, a investigação do tema é um importante instrumento no planejamento de programas de prevenção e tratamento. Foi verificada a presença do tema saúde bucal no arcabouço legislativo federal no período de 1986 a 2014. Tratou-se de pesquisa exploratória de base descritiva-analítica, que utilizou a pesquisa documental. Foram levantados nos sítios das duas casas do Congresso Nacional e do Ministério da Saúde a legislação produzida nesse período. Os resultados encontrados demonstraram que o tema saúde bucal está no grupo de normas infralegais e o tema está presente na agenda governamental. A evolução legislativa no Brasil para o alcance do direito humano ao sorriso está ascendendo, mas faltam concretizações das ações. A saúde bucal ainda permanece à margem da saúde geral.

Palavras-chave: Direito à saúde. Atenção à saúde. Saúde bucal.

ABSTRACT: Population oral health is reflected by the overall health and quality of entire society life. Oral disease patterns seem to coincide with lifestyle choices, including diets high in sugar, the use of tobacco and alcohol, physical inactivity and chronic stress. Thus, in order to plan successful prevention and treatment programs for those suffering with oral diseases, research on topic is a must. The theme of public oral health has been seen in the federal legislative framework since 1986 up until 2014. During this period, exploratory research was based on descriptive-analytics. The subject is present on the government agenda and the educational role is important to achieve the eradication of the oral disease. Oral health care is still seen as less important than the overall health.

Keywords: Right to health., Health care. Oral health.

RESUMEN: La salud oral de la población se refleja en el estado general de salud y en la calidad de vida de toda la sociedad. Los cambios en los patrones de las enfermedades están estrechamente relacionados con cambios en el estilo de vida, que incluyen las

\footnotetext{
${ }^{1}$ Cirurgiã-dentista formada pela Universidade Federal de Uberlândia. Especialista em Saúde Pública, Endodontia, Odontologia do Trabalho e Odontogeriatria. E-mail: yedaparro@gmail.com

${ }^{2}$ Psicólogo formado pela Universidade Federal do Rio de Janeiro. Analista de Gestão em Saúde da Fundação Oswaldo Cruz - Fiocruz-DF E-mail: piresguerrero@gmail.com
} 
dietas con alto contenido de azúcar, el tabaco y el alcohol, la inactividad física y el estrés crónico. Por lo tanto, la investigación del tema es una herramienta importante en la planificación de programas de prevención y de tratamiento. Se verificó la presencia del tema de la salud oral en el marco legislativo federal para el período de 1986 a 2014. Se trata de un estudio exploratorio de base descriptiva-analítica, que utilizó la investigación documental. Se pesquisó, en los sitios web de ambas cámaras del Congreso y en el del Ministerio de Salud, la legislación promulgada durante ese período. Los resultados demostraron que la temática de la salud oral está en el conjunto de disposiciones infra legales y por lo tanto, el tema está presente en la agenda del gobierno. La salud oral aún sigue al margen de la salud general.

Palabras-llave: Derecho a la salud. Atención a la salud. Salud bucal.

\section{Introdução}

A saúde bucal da população tem reflexo na saúde integral e na qualidade de vida de toda a sociedade. A melhoria dessa saúde se dá por meio da prevenção, promoção e recuperação, abrangendo também a educação. A investigação do tema é um importante instrumento no planejamento de programas de prevenção e tratamento (1).

O Brasil é conhecido pelos contrastes naturais nas suas diferentes regiões bem como pelos profundos contrates sociais e exclusão de parcela expressiva da população ao acesso aos mais elementares direitos sociais, entre eles, o direito à saúde (2).

O direito à saúde se insere na órbita dos direitos sociais constitucionalmente garantidos, tratando-se de um direito público subjetivo. No âmbito ético e jurídico o direito à saúde é considerado um direito humano, positivado no sistema legal brasileiro como um direito fundamental (3).

A saúde bucal engloba as condições biológicas e psicológicas que possibilitam o ser humano exercer as funções de mastigação, deglutição, fonação, além de estar envolvidas com a dimensão estética, auditiva e postural, possibilitando exercer a autoestima e relacionar-se socialmente sem inibição ou constrangimento (4). Essa saúde vai além de dentes saudáveis, abrange também o denominado complexo craniofacial, constituído pelas estruturas e tecidos dentários, bucais, faciais e do crânio (4).

Sendo parte importante da saúde geral, a saúde bucal

(...) é essencial para o bem-estar das pessoas, e implica estar livre de dor orofacial crônica, de câncer de boca e faringe, de alterações nos tecidos moles da boca (língua, gengivas e mucosa oral), de defeitos 
congênitos como lesões e fissuras de lábio e/ou palato e de outras enfermidades ou agravos que afetem o complexo craniofacial (4).

A saúde bucal permite falar, sorrir, beijar, tocar, cheirar, saborear, mastigar, deglutir e gritar, além de proteger contra infecções e ameaças ambientais (4). Algumas bactérias alojadas na boca podem atingir a circulação sanguínea, chegando ao coração, o que leva ao quadro de endocardite bacteriana. Assim como, se atingem o aparelho respiratório, pode haver um quadro de pneumonia. As doenças bucais implicam em restrições de atividades na escola, no trabalho e na vida doméstica, causando a perda de horas dessas atividades, a cada ano, em todo o mundo. O impacto psicológico dessas enfermidades reduz significativamente a qualidade de vida (4).

A cárie dental é o maior problema de saúde bucal e de saúde pública. O declínio na prevalência dessa doença em crianças foi uma conquista da área de odontologia, mas um olhar mais atento sobre os números já basta para observar que a cárie ainda produz perdas dentárias, levando ao edentulismo, parcial ou total, milhões de brasileiros adultos e idosos (4).

Os cuidados em saúde bucal incorporam-se à visão de organismos internacionais da agenda de Saúde para Todos, consagrada em 1978, na Declaração Internacional de Cuidados Primários em Saúde de Alma-Ata. Foi incluída nas Metas de Desenvolvimento do Milênio estabelecidas em 2000 (5). Apesar das melhorias na saúde bucal das populações de vários países, ainda percebe-se problemas persistentes graves, principalmente nos grupos de baixa renda, tanto nos países em desenvolvimento como naqueles desenvolvidos (5).

Vale ressaltar o que Moysés escreve sobre a doença cárie dental:

(...) É preciso lembrar que essa doença adquire magnitude epidemiológica associada a padrões dietéticos em que o açúcar torna-se fartamente disponível, especialmente nas sociedades que se modernizaram ao longo do século XX. Alia-se a isto o desenvolvimento de modelos de assistência odontológica de caráter curativo reparador e, muitas vezes, mutilador, em que assistência era sinônimo de extração dentária) (5).

Entre as doenças negligenciadas, citadas como problemas de saúde pública em âmbito mundial, estão as cáries dentais, doenças gengivais e periodontais, perdas 
dentais, lesões de mucosa, traumatismos bucodentais e cânceres na região de orofaringe, além de afecções bucais relacionadas com HIV/Aids (5).

As mudanças nos padrões das doenças guardam estreita relação com as alterações nos estilos de vida, que incluem dietas ricas em açúcares, uso de tabaco e álcool, sedentarismo e estresse crônico em ocupações com rotinas desgastantes. As doenças bucodentais, além dos determinantes sociais, estão associadas a esses fatores de estilo de vida, os quais são riscos para a maioria das doenças crônicas (5). "Várias dessas doenças como as cardíacas, acidentes vasculares, carcinomas e doenças bucais, têm fatores de risco em comum, e muitos deles são associados a mais de uma doença crônica." (5).

Na década de 1980, a fragilidade do setor da saúde bucal no Brasil foi evidenciada na $7^{\text {a }}$ Conferência Nacional de Saúde (CNS), abrindo caminho para a inserção da odontologia em um programa nacional de saúde e na 8ª̣S o movimento nascente da saúde bucal coletiva defendeu as diretrizes do Movimento da Reforma Sanitária (5).

Em 1989, o Ministério da Saúde do Brasil aprovou a Política Nacional de Saúde Bucal (PNSB), provocando a busca de outras bases legais para instituir uma prioridade política e orçamentária maior para o setor odontológico na esfera do Governo Federal (6).

A 2 $2^{\text {a }}$ Conferência Nacional de Saúde Bucal (CNSB), em 1993, trouxe como tema a saúde bucal como um direito de cidadania (7).

Trazendo a saúde bucal como tema indissociável da saúde geral das pessoas e como um direito de cidadania e direito humano fundamental para todos, o relatório da $3^{a}$. CNSB trouxe a possibilidade da ação da sociedade na formulação das políticas de saúde bucal, dentro dos princípios do Sistema Único de Saúde (SUS) (2).

A saúde bucal está diretamente relacionada às condições de alimentação, moradia, trabalho, renda, meio ambiente, transporte, lazer, liberdade, acesso e posse da terra, acesso aos serviços de saúde e à informação (8).

Considerando a saúde bucal como parte do conceito de direito à saúde, esse artigo objetivou verificar a participação da odontologia no arcabouço legislativo federal no período de 1986 a 2014. 


\section{Metodologia}

Foi feita uma pesquisa documental e bibliográfica levantando dados sobre o Direito à Saúde e a Atenção à Saúde Bucal no Sistema Público de Saúde do Brasil, durante o período da $8^{\text {a }}$ CNS (1986) e da $1^{\text {a }}$ CNSB (1986), percorrendo a implantação do Programa "Brasil Sorridente", marco do fortalecimento da odontologia no SUS, ocorrido nas primeiras décadas do século XXI.

Foi realizado um levantamento com base em informações entre os anos de 1986 a 2014, utilizando como campo de pesquisa as informações disponíveis nos sítios das duas casas do Congresso Nacional e do Ministério da Saúde e, ainda, pesquisa doutrinária de artigos científicos nas bases Scielo, BVS e Google acadêmico. Os descritores utilizados na coleta de todos os dados foram: Direito à Saúde, Atenção à Saúde, Saúde bucal.

A coleta geral de dados foi realizada em agosto e setembro de 2015. Como critério de inclusão, as leis federais, as portarias do Ministério da Saúde e os relatórios finais das Conferências Nacionais de Saúde Bucal foram privilegiados. Na busca para verificar como a saúde Bucal do brasileiro está sendo garantida e mostrar como influencia diretamente a saúde geral do indivíduo, a identificação dos dados foi limitada aos documentos que guardam relação direta com a promoção, prevenção e reabilitação da saúde bucal do indivíduo.

\section{Resultados e discussão}

Os resultados encontrados demonstraram que 0 arcabouço legislativo sobre esse tema está no grupo de normas infralegais. A evolução legislativa no Brasil para o alcance do direito humano ao sorriso está sedimentada nas portarias do Ministério da Saúde. Esse assunto não é diretamente abordado nas leis federais; aparece como matéria implícita na abrangência da saúde geral. As portarias são atos administrativos expedidos pelos chefes de órgãos, que encerram a manifestação da vontade do Estado e podem orientar quanto à aplicação de textos legais. Por ser ato administrativo, a portaria só tem força de lei se editada para regulamentar lei ou decreto, formalmente não é lei. Assim, o ato administrativo não se sobrepõe a lei (9). As leis federais inovam a ordem jurídica, possuem o poder de obrigar a todos, são de uso exclusivo do legislativo 
e têm características de generalidade e abstração. A portaria limita-se a desenvolver os princípios e a completar a sua dedução, a fim de facilitar o cumprimento dos dispositivos, muitas vezes genéricos, dos textos básicos (9).

Atualmente, o valor da portaria está mais prestigiado dentro do escalonamento hierárquico dos atos administrativos, liderando os demais atos editados pelo poder público, principalmente, no setor ministerial, em que se erigiu em fórmula adequada para a solução de problemas de maior relevância (9).

Segundo Delduque \& Brito (10) o direito à saúde precisa, além do respaldo constitucional, das normas infraconstitucionais elaboradas pelo Poder Legislativo para auxiliar na implementação de políticas públicas pelo Estado.

As portarias do Ministério da saúde relacionadas ao tema saúde bucal no período estudado estão listadas no quadro a seguir:

Quadro 1 - Portarias do Ministério da Saúde relacionadas ao tema saúde bucal.

\begin{tabular}{|c|c|c|c|c|}
\hline Ano & Legislação & $\begin{array}{l}\text { Documento } \\
\text { Consultado }\end{array}$ & Relação SB & Conteúdo \\
\hline 1989 & Portaria do MS & $22 / 89$ & Creme dental & $\begin{array}{l}\text { Normatizou a produção brasileira de } \\
\text { creme dental fluoretado }\end{array}$ \\
\hline 1991 & Portaria do MS & & $\begin{array}{l}\text { Procedimentos coletivos em } \\
\text { saúde bucal }\end{array}$ & $\begin{array}{l}\text { Os procedimentos coletivos reforçaram } \\
\text { as ações de caráter preventivo nos } \\
\text { serviços públicos municipais }\end{array}$ \\
\hline 2000 & Portaria do MS/GM & $1444 / 2000$ & ESB na ESF & $\begin{array}{l}\text { Saúde bucal inserida na es tratégia da } \\
\text { saúde da família }\end{array}$ \\
\hline 2001 & Portaria GMMS & $267 / 2001$ & Saúde bucal & $\begin{array}{l}\text { Regulamentou as ações das eSB na } \\
\text { eSF (equipe saúde da família) }\end{array}$ \\
\hline 2003 & Portaria do MS & $431 / 2003$ & Saúde bucal & $\begin{array}{l}\text { Nomeação de um responsável pela } \\
\text { coordenação da eSB }\end{array}$ \\
\hline 2003 & Portaria do MS & $396 / 2003$ & Saúde bucal & $\begin{array}{l}\text { Reajuste de } 20 \% \text { nos valores dos } \\
\text { incentivos financeiros para as eSB na } \\
\text { eSF }\end{array}$ \\
\hline 2003 & Portaria do MS & $673 / 2003$ & Saúde bucal & $\begin{array}{l}\text { Equiparação do teto de implantação } \\
\text { entre eSB e eSF, que era de } 1 \text { para } 2\end{array}$ \\
\hline 2004 & Portaria do MS/GM & $\begin{array}{r}318 / 2004 \\
3^{\mathrm{a}} . \mathrm{CNSB}\end{array}$ & Saúde Bucal & $\begin{array}{l}\text { Acesso e qualidade em saúde bucal, } \\
\text { superando a exclusão social }\end{array}$ \\
\hline 2004 & Portaria do MS/GM & $518 / 2004$ & Flúor & $\begin{array}{l}\text { Valor máximo permitido de fluoreto por } \\
\text { MG/L de água }\end{array}$ \\
\hline 2004 & Portaria do MS/GM & $36 / 2004$ & Saúde Bucal & $\begin{array}{l}\text { Comissão de assessoramento } \\
\text { coordenação nacional de SB }\end{array}$ \\
\hline 2004 & Portaria do MS/GM & $74 / 2004$ & $\begin{array}{l}\text { Atenção básica } \\
\text { Saúde bucal }\end{array}$ & $\begin{array}{l}\text { Reajuste dos incentivos de custeio } \\
\text { mensal das eSBI e eSBll } \\
\text { Equipo odontológico completo para as } \\
\text { eSBII } \\
\text { Moldagem, adaptação e } \\
\text { acompanhamento de próteses dentárias } \\
\text { na atenção básica }\end{array}$ \\
\hline 2004 & Portaria do MS/GM & $1570 / 2004$ & $\begin{array}{l}\text { Atenção secundária e } \\
\text { terciária }\end{array}$ & $\begin{array}{l}\text { Implantação dos CEO e laboratórios de } \\
\text { prótese }\end{array}$ \\
\hline 2004 & Portaria do MS/GM & $1571 / 2004$ & Atenção secundária e & Financiamento dos CEO \\
\hline
\end{tabular}




\begin{tabular}{|c|c|c|c|c|}
\hline & & & terciária & $\begin{array}{l}\text { Quantitativo mínimo que os CEO devem } \\
\text { realizar mensalmente }\end{array}$ \\
\hline 2004 & Portaria do MS/GM & $1572 / 2004$ & $\begin{array}{l}\text { Atenção secundária e } \\
\text { terciária }\end{array}$ & $\begin{array}{l}\text { Estabeleceu o pagam ento de próteses } \\
\text { dentárias totais } \\
\text { (limitado } 242 \text { próteses/mês) }\end{array}$ \\
\hline 2005 & Portaria do MS/GM & $283 / 2005$ & $\begin{array}{l}\text { Atenção secundária e } \\
\text { terciária }\end{array}$ & $\begin{array}{l}\text { Antecipação do recebim ento do recurso } \\
\text { de implantação dos CEO } \\
3 \text { meses para o início do funcionamento } \\
\text { após o recebimento do recurso }\end{array}$ \\
\hline 2005 & Portaria do MS/GM & $741 / 2005$ & $\begin{array}{l}\text { Atenção secundária e } \\
\text { terciária }\end{array}$ & $\begin{array}{l}\text { A odontologia deve estar em regime } \\
\text { ambulatorial e de internac̃ão (de rotina } \\
\text { e de urgência) entre as atividades } \\
\text { técnico-assistenciais na oncologia } \\
\text { (Unacon/Cacon) }\end{array}$ \\
\hline 2006 & Portaria do MS/GM & $599 / 2006$ & $\begin{array}{l}\text { Atenção secundária e } \\
\text { terciária }\end{array}$ & $\begin{array}{l}\text { Substituiu a portaria 1570/2004 } \\
\text { Estabelece critérios para o } \\
\text { credenciamento }\end{array}$ \\
\hline 2006 & Portaria do MS/GM & $600 / 2006$ & $\begin{array}{l}\text { Atenção secundária e } \\
\text { terciária }\end{array}$ & $\begin{array}{l}\text { Quantitativo mínimo que os CEO devem } \\
\text { realizar mensalmente }\end{array}$ \\
\hline 2006 & Portaria do MS/GM & $650 / 2006$ & Atenção básica & $\begin{array}{l}\text { Reajuste de } 50 \% \text { no recurso de custeio } \\
\text { para eSB }\end{array}$ \\
\hline 2006 & Portaria do MS/GM & $750 / 2006$ & Atenção básica & $\begin{array}{l}\text { Cadastramento no CNES das equipes } \\
\text { na estratégia da saúde da família (eSF, } \\
\text { eSFSB e ACS (agentes comunitários) }\end{array}$ \\
\hline 2006 & Portaria do MS/GM & $822 / 2006$ & Atenção básica & $\begin{array}{l}\text { Altera os critérios das modalidades das } \\
\text { eSF }\end{array}$ \\
\hline 2006 & Portaria do MS/SAS & $939 / 2006$ & Vigilância em saúde & $\begin{array}{l}\text { Instituição do comitê técnico ass essor } \\
\text { para estruturação e implantação da } \\
\text { estratégia de vigilância em saúde bucal } \\
\text { dentro da PNSB }\end{array}$ \\
\hline 2006 & Portaria do MS/GM & $2527 / 2006$ & Atenção básica & $\begin{array}{l}\text { Conteúdo mínimo do curso introdutório } \\
\text { para profissionais da saúde da família }\end{array}$ \\
\hline 2007 & Portaria do MS/GM & $1696 / 2007$ & Atenção básica & $\begin{array}{l}\text { Atualização do Piso da atenção básica } \\
\text { (PAB) para municípios e DF }\end{array}$ \\
\hline 2008 & Portaria do MS/GM & $90 / 2008$ & Atenção básica & $\begin{array}{l}\text { Atualização do quantitativo populacional } \\
\text { de residentes em assentamentos da } \\
\text { reforma agrária e quilombos, por } \\
\text { município, para o cálculo do teto de eSF } \\
\text { e eSB }\end{array}$ \\
\hline 2008 & Portaria do MS/GM & $648 / 2008$ & Saúde bucal & $\begin{array}{l}\text { Regulamentou a atenção básica e } \\
\text { definiu as ações de SB nesse nível de } \\
\text { atenção }\end{array}$ \\
\hline 2008 & Portaria do MS/GM & $2489 / 2008$ & Atenção básica & $\begin{array}{l}\text { Definição dos valores de financiamento } \\
\text { do Piso de Atenção Básica Variável } \\
\text { para a estratégia da Saúde da família e } \\
\text { de saúde bucal }\end{array}$ \\
\hline 2008 & Portaria do MS/GM & $3066 / 2008$ & Atenção básica & $\begin{array}{l}\text { Piso de Atenção Básica Variável para } \\
\text { estrat. SF e SB }\end{array}$ \\
\hline 2009 & Portaria do MS/GM & $2371 / 2009$ & Saúde bucal & $\begin{array}{l}\text { Instituição do componente móvel- } \\
\text { unidade odontológica móvel (UOM) }\end{array}$ \\
\hline 2009 & Portaria do MS/GM & $2372 / 2009$ & Saúde bucal & $\begin{array}{l}\text { Fornecimento de equipamentos } \\
\text { odontológicos para as eSB }\end{array}$ \\
\hline 2009 & Portaria do MS/GM & $\begin{array}{l}2373 / 2009 \\
\text { Alterou a } \\
599 / 2006\end{array}$ & $\begin{array}{l}\text { Atenção secundária e } \\
\text { terciária }\end{array}$ & $\begin{array}{l}\text { O gestor municipal pode credenciar o } \\
\text { CEO com recursos próprios }\end{array}$ \\
\hline 2009 & Portaria do MS/GM & $2374 / 2009$ & $\begin{array}{l}\text { Atenção secundária e } \\
\text { terciária }\end{array}$ & $\begin{array}{l}\text { Reajuste dos valores de referência das } \\
\text { próteses dentárias e ampliação dos } \\
\text { procedimentos possíveis de serem } \\
\text { realizados }\end{array}$ \\
\hline 2009 & Portaria do MS/GM & $3170 / 2009$ & Atenção básica & Divulgação de valores anuais e mensais \\
\hline
\end{tabular}




\begin{tabular}{|c|c|c|c|c|}
\hline & & & & da parte fixa do PAB \\
\hline 2009 & Portaria do MS/GM & $3189 / 2009$ & Saúde bucal & $\begin{array}{l}\text { Programa de formação de profissionais } \\
\text { de nível médio para a saúde (técnico } \\
\text { para SB e prótese dentária) }\end{array}$ \\
\hline 2010 & Portaria do MS/GM & $1032 / 2010$ & Saúde bucal & $\begin{array}{l}\text { Atendimento em SB das pessoas com } \\
\text { necessidades especiais em âmbito } \\
\text { hospitalar }\end{array}$ \\
\hline 2010 & Portaria do MS/GM & $3728 / 2010$ & Saúde bucal & Nomeação do coordenador de SB \\
\hline 2010 & Portaria do MS/SAS & $718 / 2010$ & Assistência odontológica & $\begin{array}{l}\text { Realização de procedimentos de } \\
\text { ortodontia e implantes no SUS }\end{array}$ \\
\hline 2011 & Portarias do MS/AS & $\begin{array}{l}1454 \text { e } \\
\text { Programa } \\
\text { Nacional de } \\
\text { melhoria do } \\
\text { acesso e da } \\
\text { qualidade da } \\
\text { atenção } \\
\text { básica }\end{array}$ & Atenção básica & $\begin{array}{l}\text { Ampliar o acesso e a melhoria da } \\
\text { qualidade da atenção básica }\end{array}$ \\
\hline 2011 & $\begin{array}{l}\text { Portarias do } \\
\text { MS/SAS }\end{array}$ & $576 / 2011$ & Atenção básica & $\begin{array}{l}\text { Estabelecer carga horária semanal para } \\
\text { médicos, dentistas e enfermeiros e } \\
\text { normas para cadastramento no SCNES } \\
\text { das equipes de atenção básica que } \\
\text { seriam do PMAQ }\end{array}$ \\
\hline 2011 & $\begin{array}{l}\text { Portarias do } \\
\text { MS/GM }\end{array}$ & $2396 / 2011$ & Saúde bucal & $\begin{array}{l}\text { Profissionais de SB podem fazer parte } \\
\text { do PMAQ-AB }\end{array}$ \\
\hline 2011 & $\begin{array}{l}\text { Portarias do } \\
\text { MS/GM }\end{array}$ & $2488 / 2011$ & Saúde bucal no SUS & $\begin{array}{l}\text { Garante o atendimento a urgências } \\
\text { odontológicas e promoçãa, prevenção, } \\
\text { assistência e reabilitação da SB }\end{array}$ \\
\hline 2011 & $\begin{array}{l}\text { Portarias do } \\
\text { MS/GM }\end{array}$ & $2490 / 2011$ & Atenção básica & $\begin{array}{l}\text { Define valores de financiamento das } \\
\text { ESFR e UBSF }\end{array}$ \\
\hline 2011 & $\begin{array}{l}\text { Portarias do } \\
\text { MS/SAS }\end{array}$ & 703 & Atenção básica & $\begin{array}{l}\text { Cadas tramento no CNES das novas } \\
\text { equipes da estratégia da saúde da } \\
\text { família }\end{array}$ \\
\hline 2011 & $\begin{array}{l}\text { Portarias do } \\
\text { MS/GM }\end{array}$ & $1602 / 2011$ & Atenção básica & $\begin{array}{l}\text { Define valor mínimo da parte fixa do } \\
\text { PAB }\end{array}$ \\
\hline 2011 & $\begin{array}{l}\text { Portarias do } \\
\text { MS/GM }\end{array}$ & $1599 / 2011$ & Atenção básica & $\begin{array}{l}\text { Define valores } \mathrm{PAB} \text { para ESF, ESB e } \\
\text { ACS }\end{array}$ \\
\hline 2011 & $\begin{array}{l}\text { Portarias do } \\
\text { MS/GM }\end{array}$ & $122 / 2011$ & Saúde bucal & $\begin{array}{l}\text { Diretrizes de organização e } \\
\text { funcionamento das equipes de } \\
\text { consultório na rua }\end{array}$ \\
\hline 2011 & $\begin{array}{l}\text { Portarias do } \\
\text { MS/GM }\end{array}$ & $12466 / 2011$ & SUS & $\begin{array}{l}\text { Acrescenta artigos à lei } 8080 / 90 \\
\text { Dispõe sobre com issões intergestoras } \\
\text { do SUS, CONASS e CONASEMS }\end{array}$ \\
\hline 2012 & Portaria do MS/GM & $3012 / 2012$ & Saúde bucal & Redefine a composição das ESB \\
\hline 2012 & Portaria do MS/GM & $3022 / 2012$ & Saúde bucal & $\begin{array}{l}\text { Recursos financeiros para } \\
\text { equipamentos odontológicos para os M } \\
\text { que implantarem a eSB }\end{array}$ \\
\hline 2012 & Portaria do MS/GM & 978/2012 & Atenção básica & $\begin{array}{l}\text { Define os valores de financiamento do } \\
\text { PAB para eSF, eSB e núcleos de apoio } \\
\text { à saúde da família }\end{array}$ \\
\hline 2012 & Portaria do MS/GM & $366 / 2012$ & Atenção básica & $\begin{array}{l}\text { Recursos para equipamentos } \\
\text { odontológicos para M que implantarem } \\
\text { a eSB }\end{array}$ \\
\hline 2012 & $\begin{array}{l}\text { Portarias do } \\
\text { MS/GM }\end{array}$ & $123 / 2011$ & Saúde bucal & $\begin{array}{l}\text { Diretrizes de organização e } \\
\text { funcionamento das equipes de } \\
\text { consultório na rua }\end{array}$ \\
\hline 2013 & Portaria do MS & $2355 / 2013$ & ESF & Cálculo do teto máximo das eSF \\
\hline 2013 & Portaria do MS & $1301 / 2013$ & Atenção básica & $\begin{array}{l}\text { Recursos para equipamentos } \\
\text { odontológicos para M que implantarem } \\
\text { a eSB }\end{array}$ \\
\hline 2013 & Portaria do MS/SAS & $17 / 2013$ & Atenção básica & Equipes de SB incluídas na tabela de \\
\hline
\end{tabular}




\begin{tabular}{|l|l|l|l|l|}
\hline 2014 & & & & tipo de equipes do SCNES \\
\hline Interministerial & $1646 / 2014$ & Saúde bucal & $\begin{array}{l}\text { Institui o Componente GraduaCEO- } \\
\text { Brasil Sorridente, que compõe a rede } \\
\text { de atenção à saúde } \\
\text {-Atendimento em todas as áreas da } \\
\text { odontologia em parceria com as } \\
\text { faculdades }\end{array}$ \\
\hline
\end{tabular}

Fonte: elaborado pela autora com base nas Portarias do Ministério da Saúde.

Bastante eficaz é o uso do flúor na prevenção da cárie dentária, pois reduz em 50\% a incidência dessa doença. Uma lei federal sancionada em 1973 obriga os municípios a fornecer esse elemento na água de abastecimento público, mas hoje ainda não é uma realidade para todas as cidades. Há uma dificuldade na parceria com os estados e municípios nesse sentido (11). Na tentativa de estender esse benefício, em 1989, foi normatizada a produção de creme dental fluoretado.

A saúde bucal entrou na estratégia da saúde da família no ano 2000 , sendo que a coordenação sobre esse tema só foi criada em 2003. A partir desse ano, a saúde bucal no SUS passou a fazer parte da agenda prioritária do governo federal. Houve um atraso na chegada formal da odontologia, que só ocorreu em 2004 com o Programa Brasil Sorridente.

Também em 2004, foram inseridas na atenção básica, secundária e terciária a moldagem e confecção de próteses dentárias assim como, com a implantação dos centros de especialidades de odontologia (CEO), as especialidades de periodontia, cirurgia e endodontia (12), indo ao encontro do tema da $3^{a}$. CNSB "Acesso e qualidade em saúde bucal, superando a exclusão social" (2). A ideia era que mais pessoas tivessem acesso aos cuidados odontológicos.

Em 2005, a portaria n. 741/2005 inseriu a odontologia em regime ambulatorial e de internação entre as atividades técnico-assistenciais no apoio multidisciplinar dos centros e unidades de assistência de alta complexidade em oncologia. Vale ressaltar que o uso de próteses muito antigas pode gerar uma série de lesões bucais, que podem progredir para lesões pré-cancerígena ou até mesmo cancerígenas (13) e que tratamentos prévios à oncoterapia devem ser realizados para minimizar a infecção local e sistêmica durante e após o tratamento do câncer. Complicações como mucosite e xerostomia são bastante comuns nesses casos. Contudo, foi só em 2008, que foram definidas as ações de saúde bucal na atenção básica. 
Em 2010, foi inserido o atendimento em saúde bucal das pessoas com necessidades especiais em âmbito hospitalar e a realização de procedimentos de ortodontia e implantes no SUS, demonstrando a inclusão social e o acesso igualitário à odontologia (2).

Os profissionais de saúde bucal somente puderam fazer parte do Programa Nacional de Melhoria do Acesso e da Qualidade da Atenção Básica (PMAQ-AB) em 2011, ano em que uma portaria garantiu a saúde bucal no SUS; vinte e três anos após a implantação desse sistema (quadro 1).

Houve um espaço de tempo grande até que o tema saúde bucal fizesse parte das conferências de saúde. Esse assunto só teve uma conferência própria em 1986 - 1a. CNSB (8), enquanto já acontecia a 8ª . CNS. Para apreciação dos relatórios das CNS e das CNSB, observe-se o quadro seguinte:

Quadro 2 - Demonstrativo dos relatórios das CNS e CNSB, projetos e programas do Ministério da Saúde relacionados diretamente com a saúde bucal.

\begin{tabular}{|c|c|c|c|c|}
\hline Ano & Legislação & Documento consultado & Relação SB & Conteúdo \\
\hline 1986 & Relatório & $8^{\mathrm{a}}$. CNS & Saúde & $\begin{array}{l}\text { - Saúde como direito de todos } \\
\text { - Saúde e democracia } \\
\text { - Conferência- Mãe do SUS }\end{array}$ \\
\hline 1986 & Relatório & $1 \stackrel{\text { a }}{ }$.CNSB & Saúde bucal & $\begin{array}{l}\text { Saúde bucal parte integrante e } \\
\text { inseparável da saúde geral }\end{array}$ \\
\hline 1988 & Política do MS & $\begin{array}{l}\text { PRECAD - Programa Nacional de } \\
\text { Prevenção da cárie dental }\end{array}$ & $\begin{array}{l}\text { Específica para } \\
\text { a odontologia }\end{array}$ & Prevenção da cárie dentária \\
\hline 1992 & Relatório & $9^{\mathrm{a}} \cdot \mathrm{CNS}$ & Saúde & $\begin{array}{l}\text { - Saúde como qualidade de vida } \\
\text { - Municipalização é o caminho }\end{array}$ \\
\hline 1993 & CNSB & $2^{\mathrm{a}}$.CNSB & Saúde bucal & $\begin{array}{l}\text { Inserção da saúde bucal no SUS, } \\
\text { acesso e equidade }\end{array}$ \\
\hline 1994 & $\begin{array}{l}\text { Programado } \\
\text { MS }\end{array}$ & $\begin{array}{l}\text { PSF - Programa da saúde da } \\
\text { família }\end{array}$ & & $\begin{array}{l}\text { Verificar mais de perto a saúde } \\
\text { do cidadão }\end{array}$ \\
\hline 1996 & Relatório & $10^{\mathrm{a}} . \mathrm{CNS}$ & Saúde & $\begin{array}{l}\text { Saúde, cidadania e políticas } \\
\text { públicas }\end{array}$ \\
\hline 2000 & Projeto do MS & SB 2000 & Saúde bucal & $\begin{array}{l}\text { Avaliar as condições de saúde } \\
\text { bucal da populacão brasileira }\end{array}$ \\
\hline 2000 & Relatório & $11^{\mathrm{a}} . \mathrm{CNS}$ & Saúde & Efetivando o SUS \\
\hline 2003 & Projeto do MS & SB Brasil 2003 & Saúde bucal & $\begin{array}{l}\text { Condições de saúde bucal da } \\
\text { população brasileira }\end{array}$ \\
\hline 2003 & Relatório & $12^{\mathrm{a}} \cdot \mathrm{CNS}$ & Saúde & $\begin{array}{l}\text {-Saúde: um direito de todos e um } \\
\text { dever do Estado } \\
\text {-A saúde que temos, o SUS que } \\
\text { queremos }\end{array}$ \\
\hline 2004 & $\begin{array}{l}\text { Programa do } \\
\text { MS }\end{array}$ & $\begin{array}{l}\text { Diretrizes para a Política Nacional } \\
\text { de Saúde Bucal }\end{array}$ & Saúde bucal & $\begin{array}{l}\text { - Inclusão da eSB no PSF } \\
\text { reforçada } \\
\text { - Criação dos CEO } \\
\text { - Organização do sistema nacional } \\
\text { de vigilância sanitária dos teores } \\
\text { de flúor } \\
\text { - Definição da área de saúde } \\
\text { bucal como uma das prioridades }\end{array}$ \\
\hline
\end{tabular}




\begin{tabular}{|c|c|c|c|c|}
\hline & & & & governamentais \\
\hline 2004 & Edital do MS & & Saúde bucal & $\begin{array}{l}\text { Para expandir a produção de } \\
\text { conhecimento básico e aplicado } \\
\text { sobre saúde bucal (SB) }\end{array}$ \\
\hline 2004 & Política do MS & $\begin{array}{l}\text { Programa Nacional de saúde } \\
\text { bucal - Brasil Sorridente }\end{array}$ & Saúde bucal & $\begin{array}{l}\text { Superar a desigualdade em } \\
\text { saúde bucal por meio da prática } \\
\text { assistencial e da qualificação dos } \\
\text { serviços oferecidos }\end{array}$ \\
\hline 2006 & Política do MS & $\begin{array}{l}\text { PNAB Política Nacional de } \\
\text { Atencão Básica }\end{array}$ & Atenção básica & Pactos pela saúde \\
\hline 2007 & Relatório & $13^{\mathrm{a}} . \mathrm{CNS}$ & Saúde & Saúde e qualidade de vida \\
\hline 2008 & Pacto & Pacto pela saúde & Saúde bucal & $\begin{array}{l}2 \text { indicadores para SB: } \\
1 \text { a. consulta programática } \\
\text { Procedimentos coletivos }\end{array}$ \\
\hline 2008 & Resolução & 406 do CNS & Saúde bucal & $\begin{array}{l}\text { Criação da comissão inters etorial } \\
\text { de SB (Cisb) para acompanhar a } \\
\text { execução da PNSB e as } \\
\text { deliberações das CNSB }\end{array}$ \\
\hline 2010 & $\begin{array}{l}\text { Pesquisa } \\
\text { nacional de SB }\end{array}$ & SB Brasil 2010 & Saúde bucal & $\begin{array}{l}\text { Base de dados permanente dos } \\
\text { indicadores de SB }\end{array}$ \\
\hline 2010 & $\begin{array}{l}\text { Decreto } \\
\text { presidencial }\end{array}$ & 7336 & Saúde bucal & $\begin{array}{l}\text { Coordenação geral de SB passa } \\
\text { a integrar o MS }\end{array}$ \\
\hline & Relatório & $14^{\mathrm{a}} . \mathrm{CNS}$ & Saúde & Todos usam o SUS \\
\hline 2011 & $\begin{array}{l}\text { Programa do } \\
\text { MS }\end{array}$ & Brasil Sorridente Indígena & Saúde bucal & Atendimento aos índios \\
\hline 2011 & Decreto & 7492 Plano Brasil sem miséria & Brasil sorridente & $\begin{array}{l}\text { Superar a extrema pobreza até o } \\
\text { final de } 2014 \\
\text {-Como meta de ampliação dos } \\
\text { serviços públicos o Brasil } \\
\text { sorridente tem destaque }\end{array}$ \\
\hline 2011 & Política do MS & Consultório na rua & $\begin{array}{l}\text { Política Nacional } \\
\text { de Atenção } \\
\text { básica }\end{array}$ & $\begin{array}{l}\text { Ampliar o acesso da população } \\
\text { de rua aos serviços de saúde }\end{array}$ \\
\hline 2015 & Relatório & $15^{\mathrm{a}} . \mathrm{CNS}$ & Saúde & $\begin{array}{l}\text { Em andamento } \\
\text { - Saúde pública de qualidade } \\
\text { Para cuidar bem das pessoas }\end{array}$ \\
\hline
\end{tabular}

Fonte: elaborado pela autora com base nos relatórios das conferências de saúde e de saúde bucal e políticas do ministério da saúde.

Em 1993, a 2a . CNSB trouxe como tema a inserção da saúde bucal no SUS, trabalhando acesso e equidade. Nesse ano, o Brasil estava entre os países de piores condições de saúde bucal no mundo (7). O SUS tinha sido criado em 1988 e, em 1993, essa conferência ainda sinalizava a inserção da saúde bucal nesse sistema.

Dois levantamentos das condições de saúde bucal da população brasileira ocorreram em 2000 e 2003, apontando a necessidade de uma providência (14), já que os resultados demonstraram uma deficiência nessa área. Assim, em 2004, houve a definição da área de saúde bucal como uma das prioridades governamentais, como ficou determinado nas diretrizes para a PNSB. Surgiu o programa Brasil Sorridente, para superar a desigualdade em saúde bucal por meio da prática assistencial e da qualificação dos serviços oferecidos (15). 
Em 2008, o pacto pela saúde determinou 2 indicadores para a saúde bucal, a 1ª . consulta programática e os procedimentos coletivos, reafirmando a presença da odontologia.

Em 2010, a pesquisa nacional de saúde bucal (16) criou uma base de dados permanente dos indicadores de saúde bucal e o decreto presidencial n. 7336 integrou a coordenação geral de saúde bucal ao Ministério da Saúde, o que mostra o quão distante estava esse tema do seu próprio ministério. O Plano Brasil Sem Miséria, em 2011, teve como destaque o programa Brasil Sorridente, meta de ampliação dos serviços públicos.

Em 2014, o Brasil chegou a 1.030 centros de especialidades odontológicas implantados e atingiu 93,6\% da meta física programada para aquele ano. Alcançou a marca de 24.279 equipes de saúde bucal (eSB) implantadas e presentes em 5.013 municípios, representando uma cobertura de $40 \%$ da população. Foram ofertadas 550.497 próteses dentárias nesse ano (12).

Em 10 anos, foram investidos mais de 7 bilhões de reais no Brasil Sorridente. Em 2002 tinham sido investidos cerca de 56 milhões na área. Esses recursos estão garantindo os cuidados de saúde bucal para muitos brasileiros (17).

$\mathrm{Na}$ década de 1970, teve o início da fluoretação das águas de abastecimento público. Mas a expansão dessa ação se deu a partir de 2004 com o Programa Brasil sorridente. Essa medida impacta a prevenção da cárie dentária em todas as faixas etárias e é um investimento barato, cerca 2 reais/ano/habitante, para prevenir uma importante lesão nos dentes. O benefício da fluoretação supera o objetivo da saúde bucal e atinge a saúde geral, pois a água potável e fluoretada é um direito de todo o cidadão (18). Em 1990, ficou definido que toda criança tem o direito de receber assistência odontológica pelo SUS. Em 2004, a incidência de cárie em crianças aos 12 anos diminuiu em 26\%. Agora em 2015, 44\% das crianças aos 12 anos estão livres de cáries. Esse resultado colocou o Brasil, de acordo com a Organização Mundial de Saúde (OMS), como um país considerado de baixa prevalência de cárie (18).

O resultado alcançado foi excelente, mostrando que o país deixou de figurar entre os países de piores condições de saúde bucal e alcançou um controle sobre a doença cárie. Entretanto, esse benefício atingiu a faixa etária menor, deixando descoberto ainda os adultos e idosos. 
O estatuto do idoso não garante a assistência odontológica a esse segmento. Aquele idoso desdentado, que se sente em situação constrangedora e com a imagem denegrida, deveria também estar protegido. O edentulismo parcial ou total, além de trazer problemas digestivos sérios, porque o alimento não é triturado corretamente, pode agravar as doenças sistêmicas do paciente. A questão protética deve ser avaliada, pois os usuários de próteses totais apresentam apenas 35\% da capacidade mastigatória e qualquer desadaptação pode reduzir ainda mais o desempenho e a eficiência mastigatória (13). A falta de dentes leva a uma projeção da cabeça para frente, podendo causar problemas na coluna. Além disso, a ausência dentária permite que a língua se espalhe no assoalho bucal, dificultando a passagem de ar, gerando problemas respiratórios. Sem dentes a boca fica mais fechada, o que determinará uma nova posição do côndilo mandibular na cavidade glenóide, levando a distúrbios na articulação têmpora mandibular, dores e a um maior número de rugas.

O artigo 16 da lei 8080/90 traz algumas competências do SUS em relação às políticas de alimentação e nutrição; aos sistemas de vigilâncias epidemiológica e sanitária e à coordenação da política de saúde do trabalhador. Verifica-se no quadro a seguir as leis federais e os decretos sobre o tema saúde:

Quadro 3 - Leis Federais e decretos sobre a saúde.

\begin{tabular}{|c|c|c|c|c|}
\hline Ano & Legislação & Documento consultado & Relaçaõ SB & Conteúdo \\
\hline 1990 & Leifederal & $\begin{array}{l}\text { 8080/90 lei orgânica da } \\
\text { saúde }\end{array}$ & & $\begin{array}{l}\text { Condições para promoção, proteção e } \\
\text { recuperação da saúde }\end{array}$ \\
\hline 1990 & Leifederal & $8142 / 90$ & & $\begin{array}{l}\text { Participação da comunidade na gestão do } \\
\text { SUS }\end{array}$ \\
\hline 1990 & Lei federal & $8069 / 90$ & $\begin{array}{l}\text { Assistência } \\
\text { odontológica }\end{array}$ & $\begin{array}{l}\text { Toda criança tem direito a receber assistência } \\
\text { médica e odontológica pelo SUS }\end{array}$ \\
\hline 2002 & Lei federal & $10465 / 2002$ & Saúde bucal & Dia nacional de Saúde Bucal - 25/10 \\
\hline 2003 & Lei federal & $\begin{array}{l}10741 / 2003 \\
\text { Estatuto do idoso }\end{array}$ & $\begin{array}{l}\text { Preservação da } \\
\text { imagem }\end{array}$ & $\begin{array}{l}\text { - Inviolabilidade da integridade física, psíquica } \\
\text { e moral } \\
\text { - Preservação da imagem e identidade }\end{array}$ \\
\hline 2008 & Lei federal & $11889 / 2008$ & Atenção básica & $\begin{array}{l}\text { Regulamentação das profissões de ASB } \\
\text { (auxiliar) e TSB (técnico) }\end{array}$ \\
\hline 2011 & Decreto & $7508 / 2011$ & SUS & $\begin{array}{l}\text { Regulamenta a lei } 8080 / 90 \\
\text { Para dispor sobre a organização do SUS, o } \\
\text { planejamento em saúde, a assistência à } \\
\text { saúde e a articulação interfederativa }\end{array}$ \\
\hline 2012 & $\begin{array}{l}\text { Lei } \\
\text { complem. }\end{array}$ & $141 / 2012$ & SUS & $\begin{array}{l}\text { Valores mínimos a serem aplicados } \\
\text { anualmente pela U,E e M em ações e } \\
\text { serviços de saúde }\end{array}$ \\
\hline 2013 & Lei federal & $12864 / 2013$ & Saúde geral & $\begin{array}{l}\text { Atividade física como determinante e } \\
\text { condicionante da saúde }\end{array}$ \\
\hline 2014 & Decreto & 8262 & Saúde & $\begin{array}{l}\text { Regulamenta a lei antifumo } \\
\text { Extingue os fumódromos }\end{array}$ \\
\hline
\end{tabular}

Fonte: elaborado pela autora com base na legislação federal. 
Nota-se o distanciamento da odontologia, quando não se alcança que um trabalhador parcial ou totalmente desdentado não pode ter um aporte nutricional adequado. A digestão inicia-se na boca e uma mastigação eficiente determina uma absorção ideal no aparelho gastrointestinal. Se for portadora de cárie dentária, doença infecto-contagiosa, de ataque quase universal, de natureza insidiosa, de caráter crônico e multifatorial, a pessoa não deveria ser considerada totalmente saudável (19). A cárie leva a perda do dente e é antecedida por síndromes agudas e crônicas, constituindo a causa direta de muitas enfermidades responsáveis pela perda de milhares de dias de trabalho por ano (20).

Com o avanço econômico da sociedade e a busca para se atingir a eficiência laboral, alguns problemas de saúde têm aparecido devido a rotina de trabalho, ao estresse e ao abandono dos cuidados com a saúde. O absenteísmo por razão odontológica é um absenteísmo - doença ainda pouco estudado (21).

Dados do IBGE (2013) demonstram que

No Brasil, $1,4 \%$ dos homens e 1,7\% das mulheres tinham grau intenso ou muito intenso de dificuldade para se alimentar por problemas nos dentes ou dentaduras. Essa dificuldade foi mais presente nos grupos de pessoas de 40 a 59 anos e de 60 anos ou mais de idade, bem como naquelas sem instrução ou com fundamental incompleto. (22)

A pesquisa estimou que, das pessoas de 18 anos ou mais de idade, $11,0 \%$ perderam todos os dentes, o que corresponde a um contingente de 16,0 milhões, sendo maior a proporção entre as mulheres $(13,3 \%)$ que entre os homens (8,4\%). Aproximadamente $41,5 \%$ das pessoas de 60 anos ou mais de idade perderam todos os dentes, tendo ocorrido o mesmo com $22,8 \%$ das pessoas sem instrução ou com fundamental incompleto. (22)

O levantamento das condições de saúde bucal da população brasileira - SB 2003 mapeou a saúde bucal do povo brasileiro e orientou a pesquisa para as ações do Brasil Sorridente. Deixou claro que em crianças e adolescentes o principal problema são cáries não tratadas, e nos adultos e idosos, a perda dentária surge como o problema mais grave (14). O relatório da $2^{a}$. CNSB (1993) reafirmava a condição indissociável da saúde bucal com todo o ser humano e garantia a assistência integral em todos os níveis e faixas etárias (7). Porém, o que se observa é que os problemas odontológicos encontrados nos idosos são complicações de processos patológicos acumulados 
durante toda a vida, devido à higiene bucal deficiente, iatrogenia, falta de orientação e de interesse em saúde bucal e ao não acesso aos serviços de assistência odontológica. Certas condições decorrentes do envelhecimento predispõem ao desenvolvimento de algumas morbidades no sistema estomatognático e o câncer bucal apresenta a variável idade como fator de risco (23). Destaca-se o caráter abrangente da atenção odontológica e a necessidade de sua integração a todos os aspectos da vida do indivíduo.

$\mathrm{Na}$ análise do quadro abaixo, que mostra o número de portarias sobre saúde bucal por ano, há que se chamar atenção para 2011. Nesse ano foram publicadas 10 portarias sobre o assunto. Percebe-se que só recentemente mais portarias discutiram esse tema. Foi uma grande produção em relação aos demais anos, considerando-se que o SUS surgiu em 1988 e o Programa Brasil Sorridente em 2004.

Quadro 4 - Número de portarias sobre saúde bucal por ano.

\begin{tabular}{|c|c|}
\hline Ano de Publicação & Número de Portarias \\
\hline 1989 & 1 \\
\hline 1991 & 1 \\
\hline 2000 & 1 \\
\hline 2001 & 1 \\
\hline 2003 & 3 \\
\hline 2004 & 7 \\
\hline 2005 & 2 \\
\hline 2006 & 7 \\
\hline 2007 & 1 \\
\hline 2008 & 4 \\
\hline 2009 & 6 \\
\hline 2010 & 3 \\
\hline 2011 & 10 \\
\hline 2012 & 5 \\
\hline 2013 & 3 \\
\hline 2014 & 1 \\
\hline
\end{tabular}

Fonte: elaborado pela autora

A prevenção em odontologia só passou a despertar interesse no Brasil no final da década de 1970, o que explica, em parte, os baixos níveis de saúde bucal, principalmente nos idosos. Os efeitos das medidas preventivas só serão evidentes nas gerações futuras dos idosos brasileiros (23). Faz-se necessário, além de recursos para a prevenção, investimentos também na educação em lugar de só se pensar nos 
procedimentos restauradores. A melhoria nas condições de saúde bucal está ligada aos valores atribuídos pela população ao tema e parece existir uma baixa autopercepção desses valores, até mesmo por falta de conhecimento. Além disso, a mudança na postura do profissional de saúde pode ser uma aliada no momento em que esse passar a ter uma conduta educadora e de valorização da saúde bucal (23).

A intervenção odontológica em nível curativo tem implicações na alimentação, na autoimagem, na autoestima, no convívio social, na fonação, na respiração e até na postura. A manutenção precária da saúde bucal pode levar a complicações, porque as doenças bucais não tratadas podem levar a infecções sistêmicas (24), como a endocardite bacteriana e a pneumonia aspirativa.

Problemas psicológicos como depressão por ausências de elementos dentais, sintomas de desadaptação, com prejuízos nos relacionamentos social, familiar, amoroso e profissional são vistos nos consultórios odontológicos. A perda dos dentes é vista como fator desencadeante de sentimentos de desamparo, impotência e diminuição de autoestima. Portanto, a substituição dos dentes perdidos está diretamente relacionada com a demanda de reconstituição da imagem pessoal e social do indivíduo (23).

A lei 8080/90 diz que são estabelecidos, no âmbito do SUS, o atendimento domiciliar para procedimentos médicos, de enfermagem, fisioterapêuticos, psicológicos e de assistência social, entre outros necessários ao cuidado integral dos pacientes em seu domicílio. Observa-se que o tratamento odontológico ainda se encontra à margem do cuidado integral (quadro 3).

O primeiro levantamento epidemiológico em saúde bucal, em 1986, forneceu dados sobre os principais problemas odontológicos na zona urbana. Foi comprovado o alto nível de cárie entre as crianças brasileiras e a pior situação entre as pessoas de menor renda. Acreditava-se, antes, que o problema era tão grande que impediriam qualquer sucesso nas propostas odontológicas de massa e por isso, levantamentos mais precisos eram desnecessários (25). Dessa forma, a saúde bucal permanecia em segundo plano.

Após 10 anos, outro levantamento foi realizado buscando verificar as alterações ocorridas no perfil da população brasileira, procurando um referencial para o desenvolvimento das ações preventivas do SUS. Houve uma discreta evolução da 
doença cárie nas crianças de 9 anos, porém era moderada ao se aproximar dos 12 anos (26). Esse fato pode ter explicação na evasão escolar.

Parte dos instrumentos normativos para a construção da PNSB foi assinada pelo Ministério da Saúde, tendo como principais atores a Presidência da República, a Comissão Intergestores Tripartite, o Conselho Nacional de Saúde e a Secretaria de Atenção à Saúde (SAS) (27). O fato do governo Federal priorizar a saúde bucal no SUS, mesmo antes do lançamento das diretrizes da PNSB, já demonstrava sinais de mudança na saúde bucal (27).

Após o lançamento da PNSB, em março de 2004, a análise normativa foi convergente aos pressupostos dessas diretrizes e às portarias, deliberações e documentos oficiais publicados. A ação orçamentária específica a partir de 2004 garantiu legitimidade à PNSB para a execução das ações (27).

O governo criou mecanismos para os estados e municípios concretizarem uma rede de atenção em saúde bucal de acesso igualitário, quando incorporou a saúde da família como estratégia na reorganização da Atenção Básica; forneceu equipamentos odontológicos, incluindo o componente móvel; implantou os CEO e laboratórios de prótese e ampliou o acesso ao atendimento hospitalar de pacientes com necessidades especiais e pacientes oncológicos. A criação e manutenção dos CEO estabeleceram, de fato, uma rede de atenção secundária de saúde bucal no SUS (27).

O SB 2010, um dos levantamentos das condições de saúde bucal da população brasileira, mostrou que a redução do número de cáries em crianças não tinha sido significativa. O resultado não foi muito expressivo em 7 anos. Entretanto, nos adultos houve uma diminuição dos componentes "perdidos" e "cariados" e aumento nos "obturados" (16). Isso mostrou uma tendência registrada no país: os procedimentos mutiladores, representados pelas extrações de dentes, cedendo espaço aos tratamentos restauradores.

Os trabalhos desenvolvidos pela coordenação geral de saúde bucal favoreceram a construção de uma política de saúde bucal com bases mais sólidas, porém frágil sob o ponto de vista do arcabouço legislativo, em comparação a outras implantadas (28).

O Brasil é o país que tem mais dentistas no mundo, no entanto o tratamento odontológico ainda é inacessível para grande parte da população. A rede pública 
precisa ser expandida, mas a dificuldade também está no tamanho do Brasil, nas diferenças regionais, que torna o acesso ao tratamento bastante complexo, e na postura do profissional que não quer ir para o interior. O SUS está com 27 anos, entretanto a implantação do Programa Brasil sorridente é recente. Nesses 11 anos de existência, as conquistas foram, entre outras, 24.000 equipes de saúde bucal (eSB) presentes em 90\% dos municípios. Antes do PNSB só as mulheres e crianças eram atendidas nos postos de saúde, hoje abrange a família toda. Esse programa é uma referência internacional e foi aprovado por $81 \%$ dos usuários. No seu início a cada 4 brasileiros de 60 anos, 3 eram desdentados (70\% sem dente), porque era proibitivo dentista particular e não havia na rede pública. A lista de espera do Brasil sorridente é extensa, porque o programa é novo e existe ainda uma demanda reprimida. O programa trabalha com 2 movimentos: deixar de produzir a doença com o uso do flúor na água e no creme dental e o tratamento (11).

O ministério da educação está cooperando com a da saúde no sentido de incentivar a formação do generalista, que pode resolver grande parte dos problemas bucais, deixando o especialista para o CEO (11). A ampliação e qualificação da atenção básica e da atenção odontológica especializada no SUS resgata as diretrizes da PNSB fundamentadas nos princípios de universalidade, equidade e integralidade. Segundo Pucca, "[..] a decisão de ampliar o acesso, a qualidade e propiciar a integralidade dos serviços de saúde bucal é o caminho correto para a redução da desigualdade no país" (28).

\section{Considerações finais}

No direito sanitário estão incluídos o direito à saúde, enquanto direito humano e o direito da saúde pública, como as normas para a promoção, prevenção e recuperação da saúde dos indivíduos. Nesse contexto a odontologia sanitária se insere, no sentido de obter as melhores condições possíveis de saúde oral.

Embora a odontologia seja uma atividade antiga no Brasil, estava relegada, por ser de execução um pouco mais complexa, de alto custo e pensada sempre de forma individual. Com a sua inclusão no programa saúde da família, a atenção básica recebeu um importante complemento e a população ganhou uma nova proposta de prática 
odontológica. A saúde bucal não resulta apenas da ação individual dos odontólogos, mas de construções sociais operadas de modo consciente, visando a coletividade, incluindo os profissionais de saúde, inclusive os dentistas. Os problemas nessa área exigem mais do que ações assistenciais de profissionais competentes, requerem políticas intersetoriais, integração de ações preventivas, curativas e de reabilitação, responsabilidade de todos os segmentos sociais e compromisso do Estado, para que o Brasil Sorridente não seja lembrado apenas como uma bandeira do governo petista, que teve o presidente Lula como garoto propaganda. A odontologia se torna parte do time à medida que é percebida como necessária.

Constata-se que a saúde bucal é um conceito pouco conhecido em sua real extensão e não pode ser reduzido à saúde dos dentes ou a considerações sobre uma ou duas enfermidades.

O papel educacional é importante para a erradicação das patologias. A população só consegue participar a partir do momento que começa a conhecer. As demandas de saúde bucal e doenças sistêmicas não possuem fronteiras e propiciar saúde bucal significa propiciar saúde geral. No intuito de fazer a população reconhecer e fazer parte dessa conquista é necessário conscientizá-la de seu importante papel na continuidade desse processo. E para que isso aconteça, a mudança comportamental do profissional de odontologia é imprescindível no sentido de ensinar o seu paciente e também enxergá-lo além da cavidade oral. Nesse aspecto, o direito fundamental e inalienável da saúde bucal tem relação direta com a valorização dessa profissão.

Outra ação que poderia ser eficaz seria a descentralização das faculdades, estimulando a interiorização do dentista, para que o atendimento odontológico chegasse a um número maior de brasileiros.

A conquista da saúde bucal e da qualidade de vida como um direito cidadão já é uma realidade, apesar desse assunto vir à tona mais de 10 anos depois do surgimento do SUS. Assegurar o acesso a todos os recursos necessários para que cuidados odontológicos sejam, efetivamente, um direito humano e social já é um assunto relevante presente na agenda governamental, embora de forma ainda um pouco discreta. 
O sorriso do brasileiro está sendo garantido, no entanto, não atinge toda a população e ainda está no arcabouço infraconstitucional. O SUS tem 27 anos, mas a saúde bucal apenas 11 .

\section{Referências}

1- Brasil. Instituto Brasileiro de Geografia e Estatística. Coordenação de População e indicadores sociais. Pesquisa Nacional de Saúde do Escolar. [Acesso em 03 out 2015]. Disponível em http://www.biblioteca.ibge.gov.br/visualizacao/livros

2- Brasil. Relatório final da 3a Conferência Nacional de Saúde Bucal: acesso e qualidade superando a exclusão social. Brasilia: Ministério da Saúde, Conselho Nacional de Saúde, 2004a.

3- Ventura M, Silva NEK. A busca da equidade no acesso à saúde: as controvérsias da internação hospitalar com diferença de classe no SUS. Cadernos lbero-Americanos de Direito Sanitário, 2015, 4 (1): 86-102.

4- $\quad$ Narvai PC, Frazão P. Saúde Bucal no Brasil: muito além do céu da boca. 21ed.Rio de Janeiro: Fiocruz; 2008.p.19

5- Moysés SJ. Saúde bucal. In Giovanella L, Escorel S, organizadores. Políticas e sistema de saúde no Brasil. 2ª .ed. Rio de Janeiro: Fiocruz, 2012. p. 705-734.

6- Brasil. Ministério da Saúde. Portaria n. 613/GM, de 13 de junho de 1989. Política Nacional de Saúde Bucal: princípios, objetivos, prioridades. Secretaria Nacional Programas Especiais de Saúde, Divisão Nacional de Saúde Bucal, 1989.

7- Brasil. Ministério da Saúde. Relatório final da 2 ${ }^{a}$ Conferência Nacional de Saúde Bucal. Conselho Nacional de Saúde, 1993.

8- Brasil. Ministério da Saúde. Relatório Final da 1a. Conferência Nacional de Saúde Bucal. Conselho Nacional de Saúde, 1986.

9- Junior JC. Valor jurídico da portaria. Revista Direito Administrativo 117: 447-459, 1974 [Acesso em 01 nov 2015]. Disponível em http://www.bibliotecadigital.fgv.br/ojs/index.php/rda/article/view/40205

10- Delduque MC, Britto E. O tema da saúde no Senado Federal: uma análise dos projetos de lei de 2011-2012. Cadernos Ibero-Americanos de Direito Sanitário, 2014; 3 (3): 94-104. 
11- Pucca Junior GA. Quem vai ao dentista. Brasilia, Televisão câmara, 24 jul 2015. Entrevista ao Programa Participação Popular. [Acesso em 20 nov 2015]. Disponível em www2.camara.leg.br/camaranoticias/TV/matérias/PARTIC IPACAO-POPULAR/492777QUEM-VAI-AO-DENTISTA.htmI

12- Brasil. Portalsaúde.saude.gov.br/índex.php/relatório-de-gestao. [Acesso em 18 nov 2015].

13- Jakymiu JRG, Corrêa G de O. Levantamento de dados de pacientes e condições das próteses totais bimaxilar confeccionadas pelo SUS no município de Pinhalzinho SC. Brazilian jornal of surgery and clinical research. 2015, 11 (1): 05-12.

14- Brasil. Projeto SB Brasil 2003: condições de saúde bucal da população brasileira 2002-2003: resultados principais. Brasilia: Ministério da Saúde, 2004, 68p.

15- Brasil. Diretrizes da Política Nacional de Saúde Bucal. Brasilia: Ministério da Saúde, 2004b

16- Brasil. Projeto SB Brasil 2010: Pesquisa Nacional de Saúde Bucal. Resultados principais. Brasília: Ministério da Saúde, 2011,92p.

17- Pucca Junior GA. Rede de Pesquisa em Atenção Primária à Saúde. Portal Saúde do Mato Grosso do Sul, 27 out 2014. [Acesso em 19 nov 2015]. Disponível em WWW.portalsaude.ufms.br

18- Pucca Junior GA. Antes \& Depois da Lei. STJ, 2 mar 2015. [Acesso em 19 nov 15] . Disponível em linharesadvogados.com.br/entrevista-coordenador-gilberto-puccasaude

19- $\quad$ Leites ACBR, Pinto MB, Sousa ER de. Aspectos microbiológicos da cárie dental. Salusvita 25(2): 239-252, 2006 [Acesso em 01 nov 2015]. Disponível em http//www.usc.br/biblioteca/salus vita/index.htm

20- Medeiros EPG, Bijella VT. Bases para a organização de programas dentais para operários. Revista Brasileira de Odontologia. 1970, 27 (166): 303-311.

21- Parro, YM, Tonissi MA. Absenteísmo por causa odontológica nos servidores do Superior Tribunal de Justiça no período de janeiro de 2006 a dezembro de 2007. [Monografia]. Brasília: Programa de Pós-Graduação em Odontologia do Trabalho, Sindicato dos Odontologistas do Distrito Federal; 2009.

22- Brasil. Instituto Brasileiro de Geografia e Estatística. Pesquisa Nacional de Saúde 2013. 2015.[Acesso em 3 out 2015]. Disponível em http://www.biblioteca.ibge.gov.br/visualizacao/livros/livro94074.pdf. 
23- Shinkai RSA, Cury ADB. O papel da odontologia na equipe interdisciplinar: contribuindo para a atenção integral ao idodo. Caderno Saúde Pública 16 (4): 1099 1109, 2000. [Acesso em $1^{\circ}$ nov 2015]. Disponível http// www.scielosp.org/pdf/csp.

24- Morais TMN, Silva A, Avi ALRO, Souza PHRS, Knobel E, Camargo LFA. A importância da atuação odontológica em pacientes internados em unidade de terapia intensiva. Revista Brasileira de Terapia Intensiva 18 (4): 412-417, 2006.

25- Brasil. Ministério da Saúde. Levantamento epidemiológico em saúde bucal: Brasil, zona urbana, 1986. Brasilia, 1988. [Acesso em 3 out 2015]. Disponível emhttp//www.dab.saude.gov.br

26- Brasil. Ministério da Saúde. Levantamento epidemiológico em saúde bucal 1996 cárie dental. Brasilia, 1996. [Acesso em 3 out 2015]. Disponível emhttp//www.dab.saude.gov.br

27- Martelli PJ deL, Menezes VGde. Estudos sobre Políticas Públicas de Saúde em Recife 2000-2012: reflexões, críticas e legados. Recife: Editora Universitária da UFPE; 2014.114p.

28- Pucca Junior G A, Paludetto Junior M, Santos LMP e Pereira MF. Avaliação da estrutura normativa da Política Nacional de Saúde Bucal - Brasil Sorridente, no período de 2003 a 2011. Revista Divulgação em Saúde para debate. 2014; 51: 86-104.

\section{Como citar este artigo:}

Parro YM, Guerrero AVP. O Direito humano ao sorriso: uma análise do arcabouço legislativo sobre a saúde bucal. Revista Cadernos Ibero-Americanos de Direito Sanitário. 2016 abr./jun, 5(2):109-130. 